\title{
Magnetic resonance imaging in chronic headache: our experiences and perspectives
}

\author{
Ukamaka Dorothy Itanyi ${ }^{1}$, Philip Chinedu Okere ${ }^{2}$, Nneka Ifeyinwa Iloanusi ${ }^{2}$, Felix U Uduma ${ }^{3}$
}

1. Department of Radiology, University of Abuja Teaching Hospital, Abuja, Nigeria.

2. Department of Radiation Medicine, Faculty of Medical Sciences, College of Medicine, University of Nigeria, Ituku-Ozalla Campus, Enugu, Nigeria.

3. Department of Radiology, Faculty of Clinical Sciences, College of Health Sciences, University of Uyo, Uyo, Nigeria.

\section{Emails:}

Ukamaka Dorothy Itanyi: E-mail: amakaitanyi@gmail.com; Philip Chinedu Okere:

Email: philip.okere@unn.edu.ng; Felix U Uduma:Email: E-mail: felixuduma@yahoo.com

\begin{abstract}
Background: Headache is a common symptomatology necessitating hospital consultations. Despite the prohibitive cost to patients in Nigeria, Magnetic resonance imaging (MRI) has become an evaluating tool for headache.

Objectives: To determine the yield of cranial MRI and frequency of significant intracranial lesions among patients with chronic headache.

Methods: A three-year retrospective analysis of cranial MR images and records of patients referred to Medicaid Diagnostic Centre in Abuja, Nigeria on account of chronic headache was done. Data was analyzed using SAS software version 9.3.

Results: 150 patients aged 9 to 73 years (mean $=39.5$ years) with chronic headache were studied. There were 54 males and 96 females with a ratio of 1:1.8. 48\% and 52\% had normal and abnormal MRI findings respectively. Although the number with abnormal MRI was higher than those with normal exams, this difference was not significant $(p=0.624)$. The commonest neoplastic and non-neoplastic abnormalities were pituitary macroadenoma (4\%) and sinusitis (21.3\%) respectively.

Conclusion: In our study, MRI had a low diagnostic yield in patients with chronic headache. Therefore, it is expedient that physicians stratify patients with chronic headache based on red flag signs to determine the need for cranial MRI in view of financial burden.
\end{abstract}

Keywords: Chronic headache; MRI; diagnostic yield; sinusitis.

DOI: https://dx.doi.org/10.4314/ahs.v20i3.56

Cite as: Itanyi UD, Okere PC, Iloanusi NI, Uduma FU. Magnetic resonance imaging in chronic headache: our experiences and perspectives Afri Health Sci. 2020;20(3): 1496-1506. bttps://dx.doi.org/10.4314/ahs.v20i3.56

\section{Introduction}

Headache is ranked among the ten most disabling conditions worldwide according to World Health Organization, (WHO) parameters. ${ }^{1}$ The lifespan prevalence of the various categories of headache varies from $31 \%$ to $96 \% .^{2,3}$

\section{Corresponding author: \\ Nneka Ifeyinwa Iloanusi, \\ Department of Radiation Medicine, \\ Faculty of Medical Sciences, \\ College of Medicine, University of Nigeria, Ituku-Ozalla Campus, Enugu, Nigeria. \\ Telephone: +2348033143023 \\ Email: nneka.iloanusi@unn.edu.ng}

Headache can be clinically described as acute, chronic or recurrent. Chronic daily headache (headache for $\geq 15$ days per month for longer than 3 months) is a common and potentially disabling condition. ${ }^{4}$ Headache is further classified into primary and secondary with regards to an underlying organic etiology. Primary headaches do not have any underlying organic pathologic aetiology and are generally benign. It has been shown that most of the patients suffering from primary headache can be managed with primary care and do not need neuroimaging in most of the cases. ${ }^{5}$ They include migraine, tension headache and cluster headaches. Conversely, secondary headaches are related to an underlying organic condition. Aetiologies of secondary headaches range from extra-cranial benign conditions such as sinusitis or mastoiditis to life-threatening intracranial pathology like subarachnoid haemorrhage or brain 
tumours. Brain tumors however account for less than $0.1 \%$ in the lifetime prevalence as a cause of headache. ${ }^{6}$ Although headache is one of the commonest presenting complaints in the general outpatient department of most hospitals, only about $10 \%$ of patients with chronic headache have a secondary cause. ${ }^{7}$ And though most causes of headaches are benign, it does not obviate the concern of the physician to alleviate the fears of patients especially in cases of chronic or recurrent headaches. In patients with chronic headaches, secondary or organic causes always need to be considered, because when present they require prompt diagnosis and possible intervention.

Treatment of headache poses a diagnostic challenge to the physician because some potential aetiologies of headache may be life threatening. It has been shown that significant intracranial pathology can cause nothing more than a mild headache. ${ }^{8}$ Neuroimaging is therefore being used as a means of triage of headaches and assuring patients with primary headaches of the absence of potentially life-threatening underlying pathologies. Presently the cost of neuroimaging in Abuja ranges from $\$ 27$ for two projections of a skull radiograph, to $\$ 118$ for a cranial computed tomography(CT) scan and \$210 for a cranial MRI (cost of neuroimaging in the index centre). In a resource-challenged environment like ours, the habitual use of cross-sectional neuroimaging, especially CT and MRI have remained controversial because data on the effectiveness of this strategy in identifying patients with treatable lesions are conflicting or lacking in developing countries like Nigeria. 9,10

MRI is often resorted to as an imaging modality of choice because of its non-ionizing property, especially with regards to the evaluation of children and pregnant females. MRI has good spatial resolution and multiplanar capabilities and demonstrates more superior soft tissue contrast than Computed Tomography (CT) scans and plain films, making it the ideal examination of the brain. In addition, some MRI studies can be done without the need of administering intravenous contrast, unlike CT or conventional angiography. MRI is more sensitive than CT in detecting intracranial pathologies and advanced techniques such as diffusion-weighted imaging, MR spectroscopy and perfusion studies, allow for enhanced characterization of lesions. ${ }^{11}$

\section{Material and method}

Ethical clearance though sought, was waived owing to the fact that our study was purely retrospective, and not involving new subjects included to the already existing data. All clerking forms, written MRI reports and brain MR images of all patients referred to Medicaid Diagnostics, a privately owned diagnostic centre in Abuja, Nigeria, over a period of 36 months, from January 2013 to December 2016, on account of chronic headache (history of headache lasting up to 3 months) were retrospectively reviewed by the authors and assigned diagnoses, irrespective of conclusions from previous reports. Some request forms contained information on the exact duration of headache, while some just indicated, $>1$ or 2 or 3 or 4 months and even up to 1 year. We therefore used a cut-off of $>3$ months. Imaging had been done with a 0.3T Toshiba MRI machine (Toshiba Medical Systems, USA, Inc). Multiplanar brain images on various sequences- T1-weighted (T1W; TE- 20ms, TR-240ms), Gadolinium diethylenetriaminepentacetate (Gd-DTPA) - enhanced T1W (TE- 20ms, TR- 240ms), T2-weighted (T2W; TE- $120 \mathrm{~ms}$, TR- 3800ms), Fluid-attenuated Inverse Recovery (FLAIR; TE- 100ms, TR- 6600ms) and Magnetic Resonance Angiography (MRA)- were used for evaluation. $7 \mathrm{~mm}$-thick slices with a field of view (FOV) of $240 \mathrm{~mm}$ were utilized for all sequences and planes. No age group was excluded from this study. No studies were excluded based on poor image quality or an inconclusive report. Subjects without a history of chronic headache were excluded from the study. Also excluded were those with known secondary causes like trauma or follow up for malignancies.

\section{Data analysis}

Data was analyzed using SAS (Statistical Analysis System) software (SAS Institute, Cary, North Carolina, USA) version 9.3. Graphical illustrations were done with SAS and MS Excel. Numerical and graphical descriptors were used to summarize the data. Numerical descriptors include mean, standard deviation, minimum, median and maximum values for continuous variables while frequency and percentage were used to describe categorical variables. Differences in age between the male and female participants were compared with two sample t-test, whereas differences in proportions of parameters were compared with the Chi-Square test. Normality of the age variable was verified using Shapiro-Wilk test $(\mathrm{p}=0.092)$. In all statistical tests, significance level was set at an alpha level of $<0.05$.

\section{Results}

A total of 2,513 brain MRI studies were reviewed, out of which 150 met the inclusion criteria- 96 female subjects $(64 \%)$ and 54 males (36\%), giving a male to female ratio of 1:1.8 (Figure 1). 


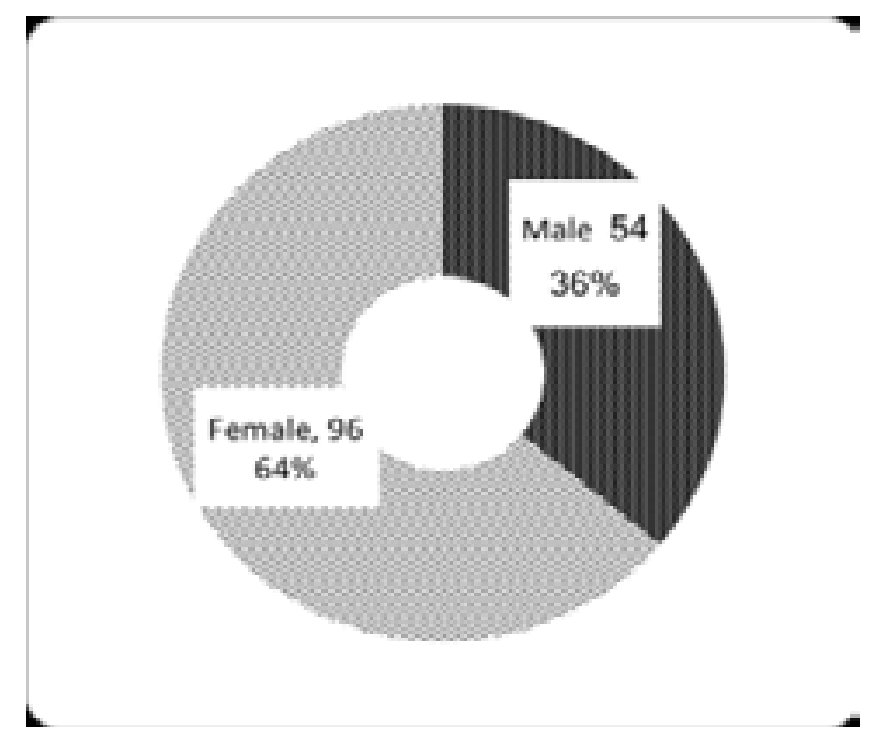

Figure 1: Pie chart depicting the distribution of subjects by gender

The age range of the subjects was 9-73 years, with most clustered between the ages of 32 and 56 years (Figure 2). The mean age was 39.5 years (Figure 3 ).

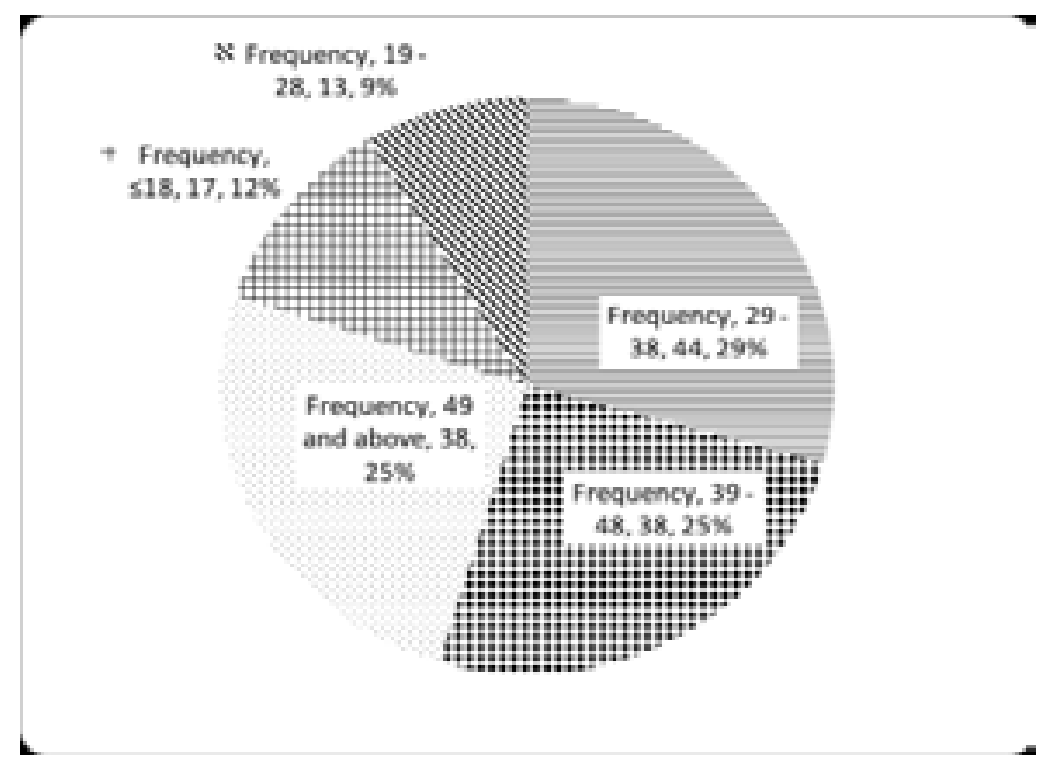

Figure 2: Pie chart showing distribution of subjects by age group 


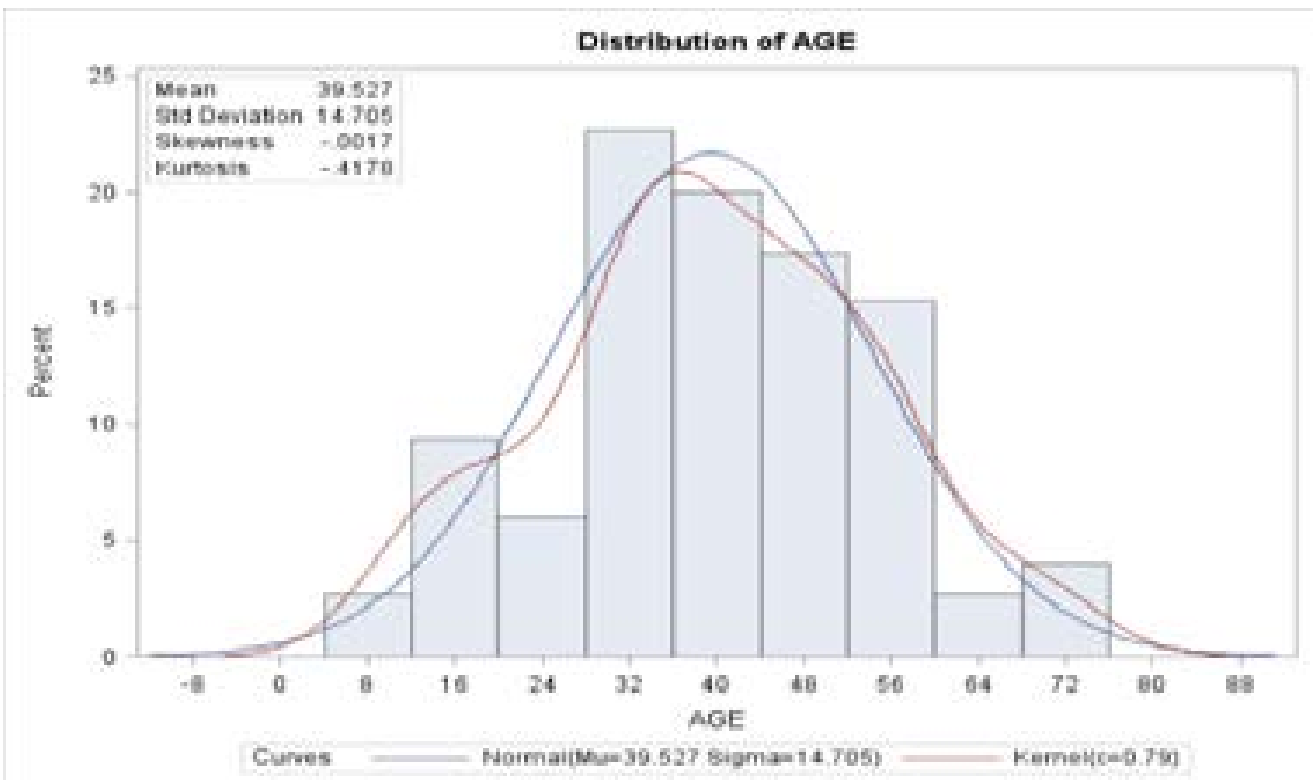

Figure 3: Histogram depicting the age distribution of the subjects

Male patients were generally older (mean age approximately 43 years) compared to the female patients (mean age approximately 37 years). There was a significant difference between the ages of patients who had nor- mal and abnormal MRI yields $(\mathrm{P}=0.0006)$. Those who had abnormal MRI yields (mean age $=43.5$ years) were generally older than those who had normal findings (mean age $=35.3$ years) $($ Table 1$)$.

Table 1: Relationship between sex and age of the patients

\begin{tabular}{lcccccc}
\hline Variable & Mean & SD & Min & Med & Max $\begin{array}{l}\text { P-value (Two-sample } \\
\text { test) }\end{array}$ \\
\hline Age (years) & 39.5 & 14.7 & 9 & 39 & 73 & \\
Male & 43.3 & 14.2 & 13 & 43 & 70 & \\
Female & 37.4 & 14.7 & 9 & 36.5 & 73 & ${ }^{a} 0.018^{*}$ \\
& & & & & & \\
\hline *Significant differences between the ages of the males and females
\end{tabular}

$72(48.0 \%)$ of the studies had no abnormality while 78 $(52 \%)$ had abnormal MRI findings. Although the number of patients who had an abnormal MRI was higher than those who had normal MRI exam, this slight difference was not statistically significant $(\mathrm{p}=0.624)$ (Table 2). 
Table 2: Relationship between sex and MRI findings

\section{N $\quad \% \quad$ P-value (Chi-Square)}

Sex

\begin{tabular}{llll} 
Male & 54 & 36.0 & \\
Female & 96 & 64.0 & \\
\hline MRI finding & & & \\
Normal & 72 & 48.0 & \\
Abnormal & 78 & 52.0 & \\
\hline
\end{tabular}

Abnormal

MRI

\begin{tabular}{lrrr} 
Male & 31 & 57.4 & \\
Female & 47 & 49.0 & $0.320^{+}$ \\
\hline
\end{tabular}

(Pearson's Chi-Square: $\mathrm{p}<0.05$ )

*Significant differences between numbers of males and females presenting for MRI.

However, no significant difference between frequency of normal and abnormal MRI

studies (') and even between the different genders in those with abnormal MRI findings $\left(^{+}\right)$

Only 36 studies (24\%) had positive intracranial findings, with intracranial tumours making up $7.3 \%$ of the total $(n=11)$. All the cases with intracranial tumors were younger than 50 years of age, with a male to female ratio of 1:2. The commonest pathology seen was sinusitis in 32 studies $(21.3 \%$ ) (Table 3$)$. Out of the $32 \mathrm{pa-}$ tients diagnosed with sinusitis, bilateral maxillary sinusitis was found in $9(28.1 \%)$, while pansinusitis occurred in $4(12.5 \%)$ (Table 4$)$.

Table 3: Various findings in cranial MRI in patients presenting with chronic headache

\begin{tabular}{|c|c|c|}
\hline Diagnosis & $\mathbf{N}$ & $\%$ \\
\hline Normal & 72 & 48.0 \\
\hline Sinusitis & 32 & 21.3 \\
\hline Sinus Polyposis & 6 & 4.0 \\
\hline Chronic Small Vessel Ischaemic Disease* & 6 & 4.0 \\
\hline Ischaemic infarct* & 6 & 4.0 \\
\hline Pituitary Macroadenoma* & 6 & 4.0 \\
\hline Idiopathic Intracranial Hypertension* & 5 & 3.3 \\
\hline Generalized Cerebral Atrophy (an unremarkable finding) & 4 & 2.7 \\
\hline Posterior Fossa Glioma* & 2 & 1.3 \\
\hline Multiple Sclerosis* & 1 & 0.7 \\
\hline Chiari 1 Malformation* & 1 & 0.7 \\
\hline Internal Carotid Artery Aneurysm* & 1 & 0.7 \\
\hline Posterior Fossa Meningioma* & 1 & 0.7 \\
\hline Glomus Jugulare Tumor* & 1 & 0.7 \\
\hline $\begin{array}{l}\text { Ruptured Aneurysm with SAH and Intracerebral } \\
\text { Heamorrhage* }\end{array}$ & 1 & 0.7 \\
\hline $\begin{array}{l}\text { Right Parietal Heamatoma with Sphenoid Sinus } \\
\text { Thrombosis* }\end{array}$ & 1 & 0.7 \\
\hline Subdural Effusion* & 1 & 0.7 \\
\hline Bilateral Fronto parietal Subdural Hygroma* & 1 & 0.7 \\
\hline Supratentorial Meningioma* & 1 & 0.7 \\
\hline Ventriculo-peritoneal shunt obstruction* & 1 & 0.7 \\
\hline Total & 150 & 100 \\
\hline
\end{tabular}


Table 4: Distribution of Sinus findings in cranial MRI

\begin{tabular}{lcc}
\hline & N & \% \\
\hline Sinusitis & 9 & 28.1 \\
Pilateral Maxillary Sinusitis & 4 & 12.5 \\
Rhinosinusitis & 3 & 9.4 \\
Left Maxillary Sinusitis & 2 & 6.3 \\
Right Maxillary Sinusitis & 2 & 6.3 \\
Ethmoidal Sinusitis & 2 & 6.3 \\
Right Fronto-Sphenoidal Sinusitis & 2 & 6.3 \\
Fronto-Sphenoidal Sinusitis & 2 & 6.3 \\
Left Ethmoidal Sinusitis & 1 & 3.1 \\
Fronto-Ethmoidal Sinusitis & 1 & 3.1 \\
Maxillary Sinusitis + Multiple Sclerosis & 1 & 3.1 \\
Chronic Bilateral Maxillary Sinusitis & 1 & 3.1 \\
Chronic Maxillary Sinusitis & 1 & 3.1 \\
Right Chronic Maxillary Sinusitis + Polyposis & 1 & 3.1 \\
\hline Total & 32 & 100 \\
\hline
\end{tabular}

\section{Discussion}

The International Headache Society has categorized headache broadly into two categories, namely primary and secondary, with secondary having an established cause.${ }^{12}$ Nevertheless, in clinical practice, certain red flag signs and symptoms should ordinarily be used in determining which patients should undergo neuro- imaging. "Red flags" for secondary headache disorders include acute onset, onset after the age of 50 years, increased frequency, severity or significant change in the usual headache pattern, new onset with an underlying medical condition (such as cancer or immunodepression), concomitant signs of systemic illness (such as fever, neck stiffness, rash), focal neurologic signs or symptoms, papilledema, and head trauma.${ }^{13}$

Local experience has been that these selection criteria are not usually followed especially when patients are referred by general practitioners or even self-referred. ${ }^{14}$ Neuroimaging ends up as a tool for triaging of patients. In our clinical practice, indications for brain imaging may include a genuine indication such as the suspicion of a structural abnormalty by the managing or referring physician or the mere compelling need to reassure worried patients or relatives. Also, self-referral is very common in privately-owned diagnostic centers usually patronized by the wealthy and enlightened who have an ever-increasing yearning for thorough and high-tech diagnostic evaluation. In a resource-poor country like ours, where on the average, a cranial MRI exam costs $\$ 210$, this is a above the means of the average patient.
Various studies have assessed the utility of Neuroimaging techniques in patients with chronic headache. ${ }^{15-18}$ These studies have reported a low diagnostic yield in patients with headache presenting for neuroimaging, and reiterated the need to consider red flag signs in selecting patients for neuroimaging. Aygun ${ }^{15}$ observed a positive diagnostic yield $(35.7 \%)$ only in those presenting with focal neurological symptoms or signs and termed this the most important clinical warning criterion (CWC) in deciding who should undergo neuroimaging. In the study done by Nepal ${ }^{16}$ the commonest abnormality was sinusitis, with positive brain parenchymal pathologies seen only in $10.1 \%$ of the subjects; mainly those with neurological deficits. Schwedt ${ }^{17}$ found that only $1.2 \%$ of children with recurrent headache required a change of management following neuroimaging, and this mainly in those with focal neurological deficits. In a study done in Port-Harcourt ${ }^{18}$, Nigeria, $90 \%$ of the patients who had cranial CT for headache, had normal findings, with only a minority having treatable intracranial lesions. The above findings tally with ours in that although $52 \%$ of the MRIs were abnormal, this apparent preponderance $(\mathrm{P}=0.642)$ was not statistically significant. More importantly, the commonest pathology observed in our study was sinusitis in $21.3 \%$. Additionally, only $24 \%$ of our subjects had positive intracranial findings necessitating urgent intervention. The other cases $76 \%$ were predominantly normal or unremarkable MRI studies. Out of the 17 children with chronic headache (See Figure 2), only 3 abnormal MRI studies (17.6\%) were found- 
posterior fossa glioma, Chiari I malformation and ventriculo-peritoneal shunt obstruction (Table 3), further reiterating the already mentioned findings in literature. Headache affects all age groups and both sexes but in general headache is twice to thrice more common in females than males. ${ }^{19}$ This is in keeping with our study which showed a slight female preponderance, with female to male ratio of $1.8: 1$. The peak age incidence of chronic headache in this study occurred in the 28-36 years age bracket. It was noted that the incidence gradually increased from the paediatric age to the 28-36 years age bracket and thereafter declined with increasing age (Figure 3). This is the trend observed in the study by Lipton et $\mathrm{al}^{19}$ in which incidence of chronic headache peaked at age 40 and thereafter declined with increasing age. Conversely, the Danish epidemiologic study ${ }^{20}$ showed a decline in the incidence of headache with increasing age, right from the paediatric age group. There was a higher yield of abnormal brain MRI images among older subjects vis-a-vis those with normal brain MRI images. This is most likely related to the higher prevalence of intracranial tumors and cerebrovascular diseases with advancing age..$^{21,22}$

Aside from the 72 normal MRIs, there were four cases with an unremarkable finding of generalized cerebral atrophy (see Table 3) which of course is unrelated to the headache the patients presented with. In this study, the commonest MRI pathology was sinusitis occurring in $21.3 \%$ of subjects (with maxillary sinus predomi- nance) (Table 3 and Figure 4). A study of 500 selected patients in Bhopal, India reiterates that though paranasal sinus disease is undoubtedly associated with headache in several cases, the cost- effectiveness of MRI or CT scan is debatable. ${ }^{23}$ Sinusitis in $11.6 \%$ of cases was the most prevalent pathology in their study occurring in the maxillary sinus in most cases. It is worthy of note that non-contrast CT is the modality of choice in evaluating patients with suspected sinusitis, while MRI is reserved for assessment of the paranasal sinuses in aggressive infection or suspected orbital or intracranial involvement. ${ }^{24}$ That said, we can safely state that our 150 subjects (most of whom were diagnosed of sinusitis) would have benefited more from cranial CT, certainly a more appropriate and economical imaging modality in our clime. Wang et al found that out of 409 patients with headache and non-focal neurological symptoms, $15(3.7 \%)$ had major abnormalities. They concluded that the yield of major abnormalities found with brain MR imaging in patients with isolated chronic headache is low but those patients with atypical headaches have a higher yield of major abnormalities and may benefit from imaging. ${ }^{25}$ A study conducted in Japan, to evaluate the efficacy of MRI for diagnosis in patients who presented with chronic or recurrent headache without any neurological deficit showed that out of a total of 306 patients, 169 patients $(55.2 \%)$ had no abnormality in the scan, 135 patients (44.1\%) had a minor abnormalities while only two patients $(0.7 \%)$ had intracranial pathology which may have been the culprit. ${ }^{26}$

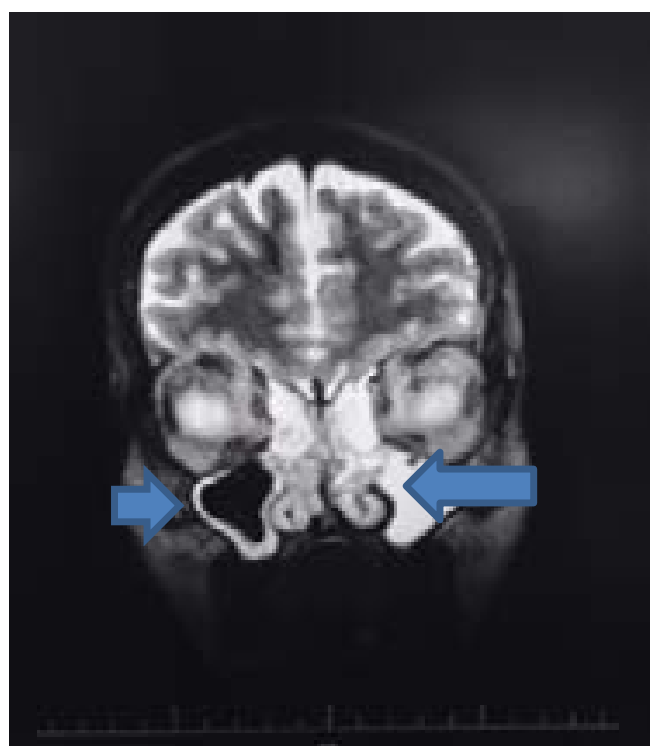

Figure 4: A coronal T2-weighted image of the head showing pan-sinusitis: The ethmoidal air cells (black stars) and the left maxillary antrum (black arrow) are filled with secretions. The right maxillary antrum (white arrowhead) demonstrates mucosal thickening. 
Chronic headache occurring after the age of 50 years is a red flag necessitating neuroimaging. ${ }^{13}$ However, in our study, all the cases with intracranial tumors (pituitary macroadenoma, meningioma, glioma, Glomus Jugulare tumour) were younger than 50 years of age, with a male to female ratio of 1:2. A similar finding was reported in another study done in the same locality, in which 11 cases of intracranial tumour were reported, with all occurring in patients aged less than 50 years, but with a male preponderance. ${ }^{27}$ In patients with brain tumours, age and sex have been demonstrated as not correlating with the presence of headache. ${ }^{28}$ Our study yielded eleven cases of intracranial tumors, comprising $7.33 \%$ of the total (Table 3) with predominance of pituitary macroadenomas (figure 5) which incidentally occurred only in females. Levy et al in his study reported that headache was a significant presentation of pituitary tumours and occurred in up to $70 \%$ of cases. ${ }^{29}$ Weingarten et al. also showed that headache associated with a brain tumour may be non-specific and frequently cannot be reliably differentiated from other more common benign causes of headache strictly on clinical grounds so in those cases neuroimaging plays an important role to include or exclude the possible cause. ${ }^{30}$ This finding is noteworthy since these tumors may have grave prognostic values and are in most cases surgically remediable.

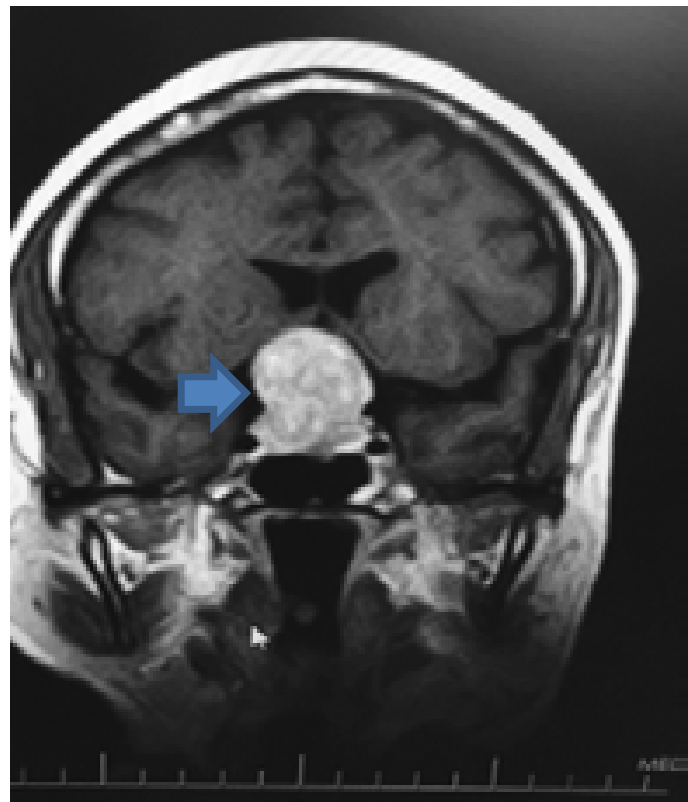

Figure 5: Contrast- enhanced coronal T1-weighted image showing a large heterogeneously enhancing sellar massa pituitary macroadenoma. (white arrowhead)
Of note also was the population of patients diagnosed with Idiopathic Intracranial Hypertension (IIH), which was seen in $3.3 \%$ of the study population. Availability of neuroimaging could account for this. In IIH, patients present with clinical signs and symptoms of raised intracranial pressure- headaches, visual problems, and pulsatile tinnitus, ${ }^{31}$ but imaging usually rules out an organic cause. On neuroimaging, subtle signs of long- standing IIH such as flattening of the posterior globes, protrusion of the optic nerve head into the posterior vitreous, optic nerve sheath swelling/tortuosity and cerebellar tonsillar herniation may be seen. ${ }^{32}$

Of significance is the demonstration of some specific organic intracranial lesions that are surgically remediable, for example intracranial meningiomas (Figure 6) and other space-occupying lesions (Table 3), thus bringing relief to the patient with chronic headache. 


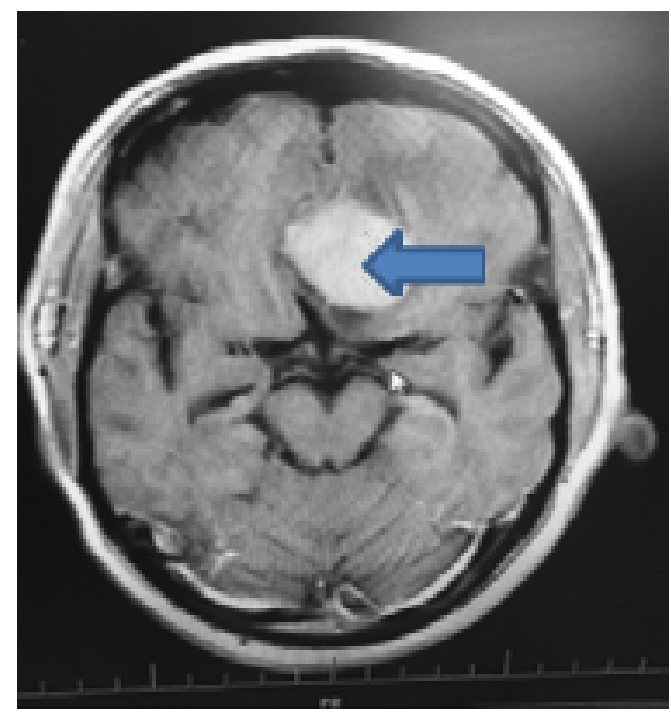

Figure 6: Axial contrast- enhanced T1-weighted image showing a left frontal para-falcine meningioma (black arrow)

\section{Conclusion}

Our study demonstrated that MRI had a low diagnostic yield in patients with chronic headache in our diagnostic centre. Paranasal sinus disease was the commonest pathology associated with chronic headache. Therefore, there is need for adequate patient stratification based on red flag signs and symptoms/clinical warning criteria to determine the real need for neuroimaging- especially MRI- in view of cost and consequent financial burden on the patients. Further well-controlled studies are needed to better understand the significance of neuroimaging in chronic headaches in our environment.

\section{Limitations of the study}

MRI machines remain relatively sparse not only in $\mathrm{Ni}$ geria, but in the entire West African sub-region. ${ }^{33}$ High maintenance costs drive up the cost of the investigation, ${ }^{34}$ limiting its availability to most patients. Computed Tomography being a cheaper modality, is a more economically viable choice for both physicians and patients. This may have had an indirect impact on sample population and variety of observed pathologies at our MRI facility. For now, this is a hypothetical assumption that requires further investigation. Also, it may be argued that our low magnetic field-strength MRI $(0.3 \mathrm{~T})$ is not comparable in image quality to higher field-strength systems and therefore could impact on diagnostic accuracy, but these low field-strength machines have been successfully guiding the management of diseases of the brain and spine in our country for many years now. ${ }^{35}$ This being a retrospective study, there were other challenges limiting the accessibility of some variables such as the exact duration of the chronic headache and the presence of red flag signs for chronic headache- focal neurological signs- from some patients' records. Also, our study did not address the relative yield between non-contrast and contrast-enhanced MRIs as such data was not harnessed.

\section{Funding}

None.

\section{Conflict of interest}

None declared.

\section{Ethical approval}

Waived.

\section{References}

1. Stovner LJ, Hagen K, Jensen R, Katsarava Z, Lipton RB, Scher AI et al. The global burden of headache: a documentation of headache prevalence and disability worldwide. Cephalalgia 2007;27(3):193-210. https://doi. org/10.1111/j.1468-2982.2007.01288.x.

2. Henry P, Michel P, Brochet B, Dartigues JF, Tison S, Salamon R. A nationwide survey of migraine in France: prevalence and clinical features in adults. GRIM. Cephalalgia 1992; 12:229-237.

3. Rasmussen BK, Jensen R, Schroll M, Olesen J. Epidemiology of headache in a general population - a prevalence study. J Clin Epidemiol 1991; 44:1147-1157.

4. Midgette LA, Scher AI. The epidemiology of chronic daily headache. Curr Pain Headache Rep; 13(1):59-63.

5. Frishberg BM, et al. Evidence-based guidelines in 
the primary care setting: neuroimaging in patients with non-acute headache. The American Academy of Neurology. Available from: URL: http://www.aan.com/public/ practice guidelines (2000). [cited on 10th August 2016]. 6. Goadsby PJ. To scan or not to scan in headache. Editorial. BMJ 2004; 329:469-470.

7. Peters KS. Secondary headache and head pain emergencies. Prim Care 2004; 31(2):381-93. https://doi. org/10.1016/j.pop.2004.02.009.

8. Schankin CJ, Ferrari U, Reinisch VM, Birnbaum T, Goldbrunner R, Straube A. Characteristics of brain tumour-associated headache. Cephalalgia 2007; 27(8):904 911.

9. Osuntokun BO, Adeuja AO, Nottidge VA, et al. Prevalence of headaches and migrainous headache in Nigerian Africans: A community based study. East Afr Med J. 1992; 69(4):196- 199.

10. Akpek S, Arac M, Atilla S, Onal B, Yucel C, Isik S. Cost effectiveness of Computed Tomography in the evaluation of patients with headache. Headache 1995; 4(35):228-230.

11. Haughton VM, Rimm AA, Sobocinski KA, et al. A blinded clinical comparison of MR imaging and CT in neuroradiology. Radiology 1986; 160:751-755 PubMed . 12. The International Classification of Headache Disorders, 3rd edition (beta version). Cephalalgia 2013;33(9):629-808. doi: 10.1177/0333102413485658.

13. Edlow JA, Panagos PD, Godwin SA, Thomas TL, Decker WW. Clinical policy: critical issues in the evaluation and management of adult patients presenting to the emergency department with acute headache. Ann Emerg Med. 2008, 52 (4): 407-436. DOI: 10.1016/j.annemergmed.2008.07.001.

14. Ezeala-Adikaibe B A, Ohaegbulam S, Iloanusi N I. Computed tomography assessment of the brain in patients with severe headache without obvious neurological deficit in South East Nigeria. West Afr J Radiol 2011; 18:38-41 PubMed .

15. Aygun D, Bildik F. Clinical warning criteria in evaluation by computed tomography the secondary neurological headaches in adults. Eur J Neurol 2003; 10(4):437-42. https://doi.org/10.1046/j.1468-1331.2003.00645.x.

16. Nepal P, Shrestha A, Ghimire N. Evaluation of CT Scan Findings in Patients Presenting with Headache. Journal of Chitwan Medical College. 2014; 3(4):9-12. http://dx.doi.org/10.3126/jcmc.v3i4.9546

17. Schwedt TJ, Guo Y, Rothner AD. “Benign” Imaging Abnormalities in Children and Adolescents with Headache. Headache 2006; 46(3):387 PubMed -398.

18. Onwuchekwa CR, Onwuchekwa AC. The Role of Computed Tomography in the Diagnostic Work -Up of Headache Patients in Nigeria. Headache 2010; 50(8):1346 PubMed -1352. https://doi.org/10.1111/ j.1526-4610.2010.01712.x.

19. Lipton RB, Stewart WF, Diamond S, Diamond ML, Reed M. Prevalence and burden of migraine in the United States: data from the American Migraine Study II. Headache 2001; 41(7):646-657.

20. Lyngberg AC, Rasmussen BK, Jørgensen T. Incidence of Primary Headache: A Danish Epidiomologic Follow-up Study. Am J Epidemiol 2005; 161:1066-1073. 21. Uduma FU, Emejulu, JKC, Moth M. Intracranial meningiomas in the present era of modern neuroimaging: diagnostic and management options with radiological illustrations. Orient J Med; 25 (3-4): 67-74.

22. Uduma FU, Okere PCN, Motah M, Kuket C, Tadze AM, Aseh C, Ongolo C. Computed tomograms of cerebrovascular accident patients in Douala, Cameroon. Jnl Medicine \& Medical Sciences. 2011; 2(9): 1075-1079.

23. Rai GS, Rai T, Jain L, Vyas MM, Roshan R. Evaluation of CT and MRI Findings among Patients Presented with Chief Complaint of Headache in Central India. J Clin Diagn Res. 2016; 10(2): TC21-TC25. doi: 10.7860/JCDR/2016/16852.7249.

24. Cornelius RS, Martin J, Wippold FJ, Aiken AH, Angtuaco EJ, Berger KL et al. ACR Appropriateness Criteria Sinonasal Disease. J Am Coll Radiol. 2013; 10(4):241246.

25. Wang HZ, Simonson TM, Greco WR, WT. Brain MR imaging in the evaluation of chronic headache in patients without other neurologic symptoms. Acad Radiol 2001;8(5):405-408.

26. Tsushima Y, Endo K. MR Imaging in the Evaluation of Chronic or Recurrent Headache. Radiology 2005; 235(2):575-579.

27. Itanyi DU, Okechukwu AA. Computed Tomography Imaging Features of Chronic Headaches in Abuja, Nigeria. Asian Journal of Medicine and Health 2017; 5(4): 1-8. DOI: 10.9734/AJMAH/2017/34713.

28. Vasguez-Barquero A, Ibanez FJ, Herrera S, Izquierdo JM, Berciano J, Pascal J. Isolated headache as the presenting clinical manifestation of intracranial tumors: a prospective study. Cephalalgia 1994;14 (4):270-271. https://doi.org/10.1046/j.1468-2982.1994.1404270.x. 29. Levy MJ, Matharu MS, Meeran K, Powell M, Goadsby PJ. The clinical characteristics of headache in patients with pituitary tumours. Brain 2005; 128: 1921 - 1930 PubMed .

30. Weingarten S, Kleinman M, Elperin L, Larson EB. The effectiveness of cerebral imaging in the di- 
agnosis of chronic headache. Arch Intern Med 1992; 152(12):2457-2462.

31. Akay R, Kamisli O, Kahraman A, Oner S, Tecellioglu M. Evaluation of aqueductal CSF flow dynamics with phase contrast cine MR imaging in idiopathic intracranial hypertension patients: preliminary results. Eur Rev Pharmacol Sci 2015;19:3475-3479.

32. Bidot S, Saindane AM, Peragallo JH, Bruce BB, Newman NJ, Biousse V. Brain Imaging in Idiopathic Intracranial Hypertension. J Neuroophthalmol 2015; 35(4):400-411. doi:10.1097/WNO.0000000000000303.

33. Ogbole GI, Adeyomoye AO, Badu-Peprah A,
Mensah Y, Nzeh DA. Survey of Magnetic Resonance Imaging Availability in West Africa. Pan African Med J 2018; 30: 240. doi:10.11604/pamj.2018.30.240.14000 PubMed .

34. Saidu SA, Umar FK. The Challenges of Running Magnetic Resonance Imaging Services in the Tertiary Health Centers of Nigeria. KJMS. 2016;(10)2: 83-87.

35. Ogbole G, Adeleye A, Adeyinka A, Ogunseyinde O. Magnetic Resonance Imaging: Clinical experience with an open low-field-strength scanner in a resource challenged African state. J Neurosci Rural Pract 2012;3(2):137143. doi:10.4103/0976-3147.98210. 